\title{
THE INCIDENCE OF ATRIAL SEPTAL DEFECT IN ADULTS
}

\author{
BY \\ W. A. SELDON, C. RUBINSTEIN, AND A. A. FRASER \\ From the Anti-Tuberculosis Association of N.S.W. Chest Clinic, Sydney, Australia \\ Received February 21, 1962
}

The incidence of atrial septal defect can be estimated from two studies of heart disease in childhood (Gardiner and Keith, 1951; Carlgren, 1959), but there has been no published survey of the frequency of this condition in the general adult population. The estimated frequency of the lesion in one of these studies was based on the number of patients attending heart clinics and could not take into account the undiagnosed cases in the population. Atrial septal defect is particularly likely to be missed on routine examinations because of the less flamboyant nature of the physical signs compared with other congenital lesions, and so the yield of this condition from school medical examinations and routine checks by the family doctor is likely to be very incomplete. A further error is introduced by the fact that this diagnosis is not always easy to make in young children on clinical, cardiographic, and radiological evidence alone, and this may act in a positive or negative direction depending on the attitude of the clinician. Lastly there is a fairly high death rate amongst patients with primum-type defects in early childhood (Bedford, 1960) so that the incidence will vary considerably in different age groups. For all these reasons the estimated frequency of this lesion may be inaccurate, and the figures produced vary widely from 1 per 2500 (Carlgren, 1959) to 1 in 8500 (Gardiner and Keith, 1951) of the child population.

It is well recognized that the radiological signs of atrial septal defect are the most striking features of the condition in adults and a radiological case-finding programme should yield good results. The Anti-Tuberculosis Association of New South Wales has been conducting mass X-ray surveys of the general adult population for some years and use has been made of their organization in the present study.

\section{FINDINGS}

The system adopted is as follows. X-rays are taken on $70 \mathrm{~mm}$. film and are read by a radiologist and a chest physician independently. If either reader considers the heart shadow abnormal the film is referred to a cardiologist who recalls for examination any person whose X-ray is considered abnormal or doubtful. Patients with evidence of heart disease are then referred to cardiac clinics for full investigation.

In the survey under consideration 502,000 persons were X-rayed out of a total eligible population of 890,000 , the eligible population being all people over 14 years of age. Amongst these 502,000 twenty-five previously undiagnosed cases of atrial septal defect were discovered.

At the same time a questionnaire was sent to 81 patients with atrial septal defect who were attending cardiac clinics in Sydney, asking them if they had ever had an X-ray taken by a Mass Survey Unit and, if so, whether their lesion had been detected. All but 8 replied but 6 had not had such an X-ray. Of the 67 persons who had been X-rayed $53(79 \%)$ had been notified that their heart was abnormal and $14(21 \%)$ had received no notification. 
It seems reasonable to assume that the same proportion of cases would be diagnosed in the present survey. This means that for the 25 cases detected there would be 6 undetected, giving a total of 31 in the 502,000 persons X-rayed or 55 in the total population of 890,000 .

In addition, a search of the records of the major Sydney hospitals revealed 57 patients with diagnosed atrial septal defects who lived in the area covered by the survey, and were over the age of 14 years, but who had not presented themselves for X-ray as they were already being X-rayed regularly at the hospital. A questionnaire sent to cardiologists revealed that 26 other patients with atrial septal defect from the same areas had attended private cardiologists only. This gives a total of 138 cases amongst 890,000 persons, an incidence of 1 in 6500 (Table I).

TABLE I

Incidence of Atrial Septal Defect in a Population of 890,000

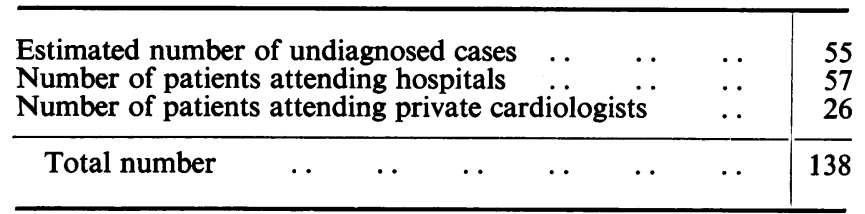

In a sample of 100,000 members from the total group X-rayed the male: female ratio was $54: 46$, compared with 51:49 in the general population (Statistical Register of N.S.W. for 1957). In another sample of 38,000 persons from the study the proportion who were over the age of 65 years was 13 per cent. This is exactly the expected percentage of this age group as calculated from figures given by the Government Statistician (Statistical Register of N.S.W. for 1957) for the general population over the age of 14 years, and it indicates that our results were not affected by an undue proportion of older people with a low incidence of atrial septal defect.

\section{Discussion}

The persons attending this X-ray survey were an unselected group from a metropolitan area where a great deal of publicity and encouragement is given to this form of campaign against pulmonary tuberculosis. The sample investigated for sex and age distribution indicate that in both respects those X-rayed were reasonably representative of the general population.

Atrial septal defect is rare in persons over the age of 65 and in our series there were in fact none over the age of 61 years. As 13 per cent or 111,000 of the X-rayed group were over the age of 65 , the 135 cases of A.S.D. were distributed amongst the remaining 779,000 giving an incidence of 1 in 5700 approximately.

Selection has occurred in this investigation in only one aspect as far as can be judged, namely, that by the nature of the $\mathrm{X}$-ray survey mongols and other mental defectives in institutions will have been excluded. Atrial septal defect is a relatively frequent concomitant of mongolism. It has been estimated that roughly 19 per cent of mongols have congenital heart defects and perhaps half of these involve the atrial septum (Berg, Crome, and France, 1960). Benda (1946) cites the incidence of mongolism as 2 to 3 per 1000 births, and if as estimated 10 per cent of these have atrial septal defects there would be at least an extra case per three or five thousand births to be added to the figures we have obtained.

The wide variation in the figures reported by other authors (Table II) might be due to a number of causes. All the series contained relatively large numbers of patients so that the possibility of significant statistical fluctuations can be discounted. Campbell (1961) by an indirect method estimated it at about 1 per 1000, but agrees this may be too high, because it assumes that all patients are equally likely to survive infancy and many malformations are much more lethal than A.S.D. Gardiner and Keith's (1951) estimated incidence is almost certainly too low due to failure to diagnose mild cases of this condition in early childhood. On the other hand it is difficult to reconcile the present figures with those of Carlgren (1959), especially as his figures do not appear to include 
mongols whom he shows as having mainly undiagnosed lesions. It is possible that our estimate of the percentage of cases detected by the X-ray survey was too high but every effort was made to get a true estimate of this, and it does not seem likely that any large error occurred here. It is recognized that patients with atrial septal defect may have relatively normal X-rays if the degree of left-to-right

TABLE II

InCidence of Atrial Septal Defect

\begin{tabular}{|c|c|c|c|c|c|}
\hline & & & Place & Age group & Incidence \\
\hline \multicolumn{2}{|c|}{ Gardiner and Keith (1951) } & . & Toronto & $0-15$ years & $1: 8500^{*}$ \\
\hline Carlgren (1959) & $\cdots$ & $\cdots$ & $\begin{array}{l}\text { Gothenburg } \\
\text { Sweden }\end{array}$ & $7-16$ years & $1: 2500^{*}$ \\
\hline This series & $\cdots$ & $\cdots$ & $\begin{array}{l}\text { Sydney } \\
\text { Sydney }\end{array}$ & $\begin{array}{l}\text { Over } 14 \text { years } \\
15-65 \text { years }\end{array}$ & $\begin{array}{l}1: 6500 \\
1: 5700\end{array}$ \\
\hline
\end{tabular}

* Calculated from figures given by author.

shunt is small, as illustrated in Fig. 1 and 2. However, patients with very small defects are also very difficult to diagnose by other means and one would not expect that this would lead to any large discrepancy between results in series studied ante-mortem.

The explanation may be that there is a true difference between the incidence of atrial septal defect

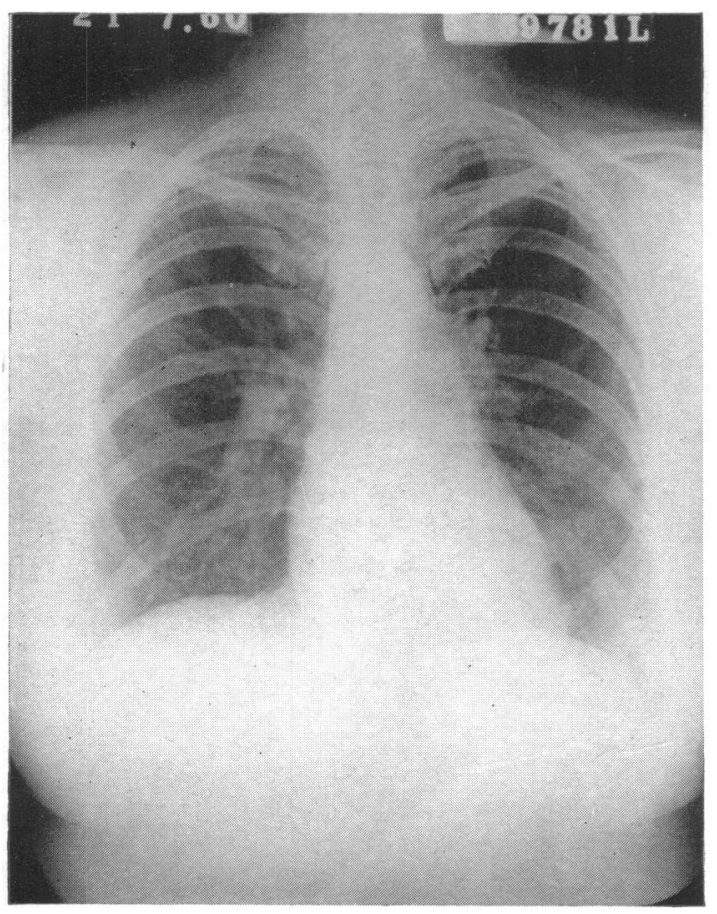

FIG. 1.-Chest X-ray of a 51-year-old woman with an atrial septal defect, normal pulmonary arterial pressure, and a pulmonary blood flow one and a half times greater than the systemic flow. There are no grossly abnormal radiological appearances.

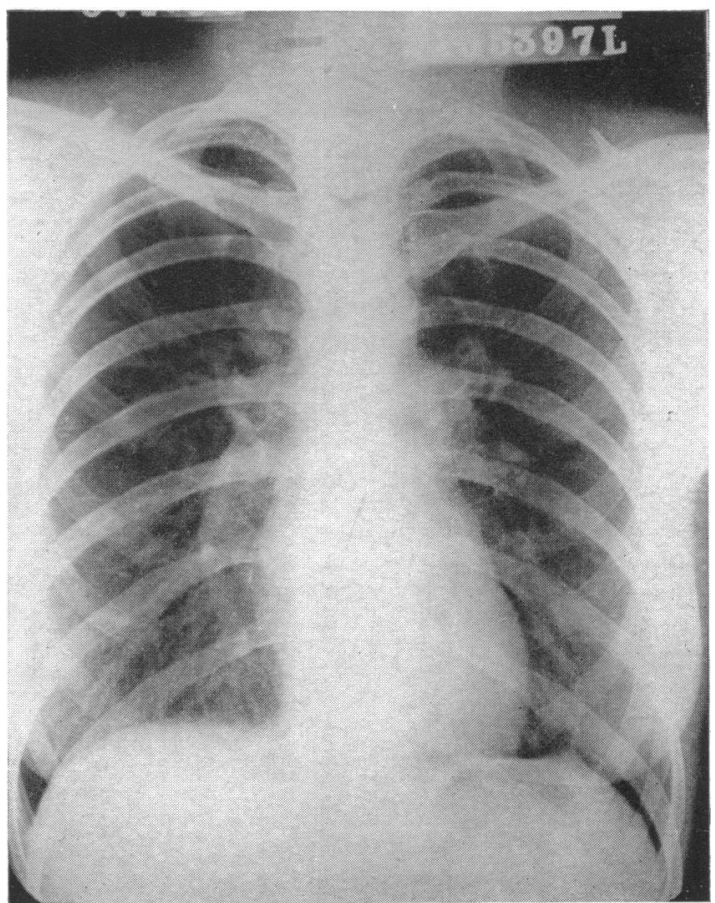

Fig. 2.-Chest X-ray of a 26-year-old woman with an atrial septal defect, normal pulmonary arterial pressure, and a pulmonary blood flow twice the systemic flow. The heart shadow was considered to be normal in size and shape. 
in Gothenburg and in Sydney, related to environmental or hereditary causes. In view of the knowledge that genetic factors do play a part in the occurrence of congenital heart disease (Campbell, 1959 ) it would not be surprising if these led to a different incidence in various races.

A check of the radiographs of the 21 per cent of patients whose lesions had not been detected at mass X-ray showed that in the majority this failure was due to errors on the part of the radiologist and the second reader. However, in a few instances such as the two illustrated in Fig. 1 and 2, the heart shadows appeared to be within normal limits of size and shape even when the diagnosis was known.

An interesting fact emerging from this investigation is that in Sydney in 1958, with open-heart surgery well established, almost 40 per cent of patients with atrial septal defect were still undiagnosed. This is probably due to the fact that they have no symptoms and that the lesion is clinically unobtrusive. The study also emphasizes the efficiency of a mass X-ray survey in detecting this condition.

\section{SUMmary}

The incidence of atrial septal defect in the adult population of Sydney has been calculated from the number of cases discovered in an X-ray survey of 502,000 people. It was found that 79 per cent of all patients with atrial septal defect were diagnosed on the $\mathrm{X}$-ray findings, and the figures were corrected for this. The final estimate of the incidence in adults between 15 and 60 years was 1:5700. From a comparison of this and the incidence reported from Sweden by Carlgren it is thought that there may be a racial difference in the frequency of this lesion.

We wish to thank the President and Board of Directors of the Anti-Tuberculosis Association of New South Wales for permission to use the records and facilities of the Association in this investigation.

\section{REFERENCES}

Bedford, D. E. (1960). The anatomical types of atrial septal defect: their incidence and clinical diagnosis. Amer. J. Cardiol., 6, 568.

Benda, C. E. (1946). Mongolism and Cretinism. Heinemann, London.

Berg, J. M., Crome, L., and France, N. E. (1960). Congenital cardiac malformations in mongolism. Brit. Heart J., 22,331 .

Campbell, M. (1959). Factors in the ætiology of atrial septal defect. Brit. Heart J., $21,65$.

(1961). The genetics of congenital heart disease and situs inversus in sibs. Brit. Heart J., $23,481$.

Carlgren, L. (1959). The incidence of congenital heart disease in children born in Gothenburg 1941-1950. Brit. Heart J., 21, 40.

Gardiner, J. H., and Keith, J. D. (1951). Prevalence of heart disease in Toronto children: $1948-49$ cardiac registry. Pediatrics, 7, 713.

Statistical Register of New South Wales for 1957-Population and Vital Statistics. N.S.W. Government Printer. 